\title{
Prevalence and Pattern of Migraine, Tension Type Headache and Chronic Daily Headache among Medical and Nursing Students in Enugu, South East Nigeria
}

\author{
0. S. Ekenze1, B. A. Ezeala-Adikaibe ${ }^{1,2 *}$, C. Orjioke' ${ }^{2}$, N. Mbadiwe ${ }^{1}$, U. N. Ijoma ${ }^{1}$, C. Onyekonwu',

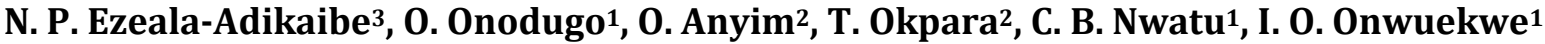 \\ ${ }^{1}$ Department of Medicine, University of Nigeria Teaching Hospital, Enugu, Nigeria \\ ${ }^{2}$ Department of Medicine, Enugu State University of Science and Technology, Enugu, Nigeria \\ ${ }^{3}$ Department of Community Medicine, University of Nigeria Teaching Hospital, Enugu, Nigeria \\ Email: ^birinusadikaibe@gmail.com
}

How to cite this paper: Ekenze, O.S., Ezeala-Adikaibe, B.A., Orjioke, C., Mbadiwe, N., Ijoma, U.N., Onyekonwu, C., Ezeala-Adikaibe, N.P., Onodugo, O., Anyim, O., Okpara, T., Nwatu, C.B. and Onwuekwe, I.O. (2018) Prevalence and Pattern of Migraine, Tension Type Headache and Chronic Daily Headache among Medical and Nursing Students in Enugu, South East Nigeria. Health, 10, 1283-1293.

https://doi.org/10.4236/health.2018.101009 $\underline{9}$

Received: September 15, 2018

Accepted: October 8, 2018

Published: October 11, 2018

Copyright $\odot 2018$ by authors and Scientific Research Publishing Inc. This work is licensed under the Creative Commons Attribution International License (CC BY 4.0).

http://creativecommons.org/licenses/by/4.0/

c) (i) Open Access

\begin{abstract}
Aim: To assess the lifetime prevalence of tension-type headache, migraine and chronic daily headache, including the primary headaches in a student population. Methods: This is a cross-sectional descriptive study. Data were collected from consecutive consenting students by means of a semi-structured questionnaire. The questionnaire was designed to assess demographic data, headache profiles and medical consultation. Results: Four hundred and forty-nine (89.8\%) out of 500 students who were interviewed were analyzed. The lifetime prevalence of primary headache was $89.8 \%$; it $90.5 \%$ and $88.6 \%$ in females and males respectively. The overall prevalence of migraine was $8.9 \%$, with a prevalence of $10.6 \%$ in females and $6.5 \%$ in males. Migraine without aura was most commonly seen at $73 \%$. The prevalence of migraine without aura was $7.6 \%$ in females and $4.9 \%$ in males. Tension type headache (TTH) had an overall prevalence of $22.9 \%$, with a prevalence of $28.4 \%$ in females and $15.1 \%$ in males. Migraine and tension type headache co-existed in $5.8 \%$ of the students. About $8.5 \%$ suffered from chronic daily headache: chronic migraine $2.9 \%$, chronic tension headache $3.1 \%$. The rate of medical consultation was $54.8 \%$ (males $49.7 \%$, females $58.3 \%$ ). Conclusions: Headache is a common health problem among medical and nursing students in Enugu South East Nigeria where $89.8 \%$ of respondents have had primary headaches. The prevalence of migraine, TTH and chronic daily headache was $8.9 \%, 22.9 \%$ and $8.5 \%$ respectively. Headaches therefore, represent one of the most challenging neurological disorders in Sub-Saharan Africa where most sufferers do not have access to specialist care.
\end{abstract}




\section{Keywords}

Primary Headache, Migraine, Tension Headache, Chronic Daily Headache

\section{Introduction}

Headache is a common neurological disorder with variable intensity [1]-[15], and one of the commonest reasons for neurology outpatient clinic consultation in Nigeria [2] [5] [6] [8]. Globally, the percentages of the adult population with an active headache disorder are $46 \%$ for headache in general, $11 \%$ for migraine, $42 \%$ for tension-type headache and 3\% for chronic daily headache [15]. In Africans, the mean prevalence of current headache is $21 \%$ for headache in general and $5 \%$ for migraine with a corresponding lifetime prevalence of $51 \%$ and $5 \%$ respectively [15]. The reported prevalence rates and pattern of primary headache disorders in Nigeria are shown in Table 1 and varied from between studies and the sample population studied.

Headache burden may vary depending on the group studied. Special groups medical and nursing like students are exposed to a lot of mental and physical stress because of the type of the profession they have chosen. Studies among students generally have shown high rates of primary headaches [1] [2] [3] [7].

Few studies have reported on the prevalence of chronic daily headache $(\mathrm{CDH})$ in Sub Saharan Africa (SSA). Hainamot et al. [16] reported a low prevalence of $1.7 \%$ in Ethiopia while higher prevalences of $11.5 \%$ and $17 \%$ were reported in Zambia [17] and Nigeria [1]. Chronic tension type headache (CTTH) and

Table 1. Headache studies in Nigeria.

\begin{tabular}{cccccccc}
\hline & Year & $\begin{array}{c}\text { Sample } \\
\text { size }\end{array}$ & $\begin{array}{c}\text { Population } \\
\text { studied }\end{array}$ & $\begin{array}{c}\text { Primary } \\
\text { headache (\%) }\end{array}$ & $\begin{array}{c}\text { Migraine } \\
(\%)\end{array}$ & $\begin{array}{c}\mathrm{TTH} \\
(\%)\end{array}$ & $\begin{array}{c}\mathrm{CDH} \\
(\%)\end{array}$ \\
\hline Osuntokun [9] & 1982 & 903 & $\mathrm{GP}^{*}$ & $\mathrm{~ns}^{\beta}$ & 4.6 & $\mathrm{~ns}^{\beta}$ & $\mathrm{ns}^{\beta}$ \\
Osuntokun [11] & 1992 & 18,954 & $\mathrm{GP}^{*}$ & 51 & 5 & $\mathrm{~ns}^{\beta}$ & $\mathrm{ns}^{\beta}$ \\
Longe [10] & 1988 & 2925 & $\mathrm{GP}^{*}$ & $\mathrm{~ns}^{\beta}$ & 6.3 & $\mathrm{~ns}^{\beta}$ & $\mathrm{ns}^{\beta}$ \\
Orji [12] & 1997 & 4398 & $\mathrm{Children}^{\beta}$ & $\mathrm{ns}^{\beta}$ & 6.4 & $\mathrm{~ns}^{\beta}$ & $\mathrm{ns}^{\beta}$ \\
Kolawale [3] & 2009 & 1513 & $\mathrm{USt}^{* *}$ & $\mathrm{~ns}^{\beta}$ & 29.9 & $\mathrm{~ns}^{\beta}$ & $\mathrm{ns}^{\beta}$ \\
Ojini [7] & 2009 & 523 & $\mathrm{MS}^{* * *}$ & 46 & 6.4 & 18.1 & $\mathrm{~ns}^{\beta}$ \\
Ofovwe [14] & 2010 & 1679 & $\mathrm{SS}^{\# *}$ & 19.5 & 13.5 & $\mathrm{~ns}^{\beta}$ & $\mathrm{ns}^{\beta}$ \\
Oshinaike [8] & 2013 & 402 & $\mathrm{HW}^{\#}$ & 39.3 & 7.4 & 28.6 & $\mathrm{~ns}^{\beta}$ \\
Onwuekwe [6] & 2014 & 133 & $\mathrm{HW}^{*}$ & 64.7 & $\mathrm{~ns}$ & $\mathrm{~ns}^{\beta}$ & $\mathrm{ns}^{\beta}$ \\
Ezeala-Adikaibe [1] & 2012 & 180 & $\mathrm{MS}^{* * *}$ & 88.3 & 18.1 & 36.8 & 17 \\
Ezeala-Adikaibe [13] & 2014 & 940 & $\mathrm{GP}^{*}$ & 66.7 & 6.4 & 13.8 & $\mathrm{~ns}^{\beta}$ \\
Ezeala-Adikaibe & $\mathbf{2 0 1 6}$ & $\mathbf{4 9 9}$ & $\mathrm{MNS}^{* * *}$ & $\mathbf{8 9 . 9}$ & $\mathbf{8 . 9}$ & $\mathbf{2 2 . 9}$ & $\mathbf{8 . 5}$ \\
\hline
\end{tabular}

${ }^{*}$ GP general population; ${ }^{* *}$ USt University students; ${ }^{* * *}$ MS medical students; ${ }^{* *}$ Secondary school studentsl; ${ }^{*}$ HW hospital workers; ${ }^{\beta}$ ns not specified; ${ }^{\delta}$ current study; ${ }^{* * *}$ MNS Medical and nursing students. 
chronic migraine (CM) account for approximately $60 \%$ - 99\% among the CDH population [18]-[24] and may pose a considerable challenge to the sufferers and physicians especially in resource poor settings with few headache specialists [3] [25] [26] [27] [28] [29].

Although one study documented a prevalence of $17 \%$ for CDH in Nigeria [1], the prevalence of CM and CTTH in the country is not known. The current prevalence of primary headaches among Africans may be underestimated because patients suffering from chronic neurological disorders present very late to doctors and sometimes never do so [30].

The aim of this study therefore was to determine the prevalence and pattern of primary headache: migraine, TTH and $\mathrm{CDH}$ among medical and nursing students in Enugu, South East Nigeria.

\section{Methods}

\subsection{Study Sample.}

This study was carried out among medical and nursing students in two Medical and Nursing schools in Enugu metropolis, South East Nigeria. The students were selected from two Teaching hospitals in the city. Medical students who were doing clinical postings from both schools and all nursing students were selected for the study. The total number of students in this category was estimated to be 650 - 750 from both schools. This study was part of a health awareness campaign in June 2015. Study duration was 2 weeks.

\subsection{Study Design}

Sample size was calculated using the formula: $\mathrm{N}=\mathrm{D} \times \mathrm{Z}^{2} \times \mathrm{P}(1-\mathrm{P}) / \mathrm{d}^{2}$. Where $\mathrm{N}=$ desired sample size. $\mathrm{P}=$ prevalence rate of migraine $6.4 \%, \mathrm{D}=$ design effect $=2$, and $\mathrm{d}=$ desired precision limit assumed at $5 \% . \mathrm{N}=2 \times(1.96)^{2} \times 0.064 \times$ $0.936 / 0.0025=2 \times 3.8416 \times 0.040704 / 0.0025=125$. Assuming $10 \%$ attrition, a sample size of 137 and above was used. A meeting was first organized with the class leaders for proper sensitization of the students before the data collection. On the day of the study, informed consent was obtained from students after explaining to them the aims and objectives of the study. A custom designed multiple-choice questionnaire designed by one of the authors (BAE) (with sections on general information about the students such as age and sex, general information on headache pain characteristics and headache profiles according to ICHD-III beta [31] and medical consultation) was self-administered and retrieved the same day. A clinic-based validation of a subset of a random sample of 30 screened individuals (20 positives, 10 negatives) was assessed by a neurologist. The questionnaire exhibited an overall $98 \%$ sensitivity (100\% for migraine and $95 \%$ for tension headache) and $95 \%$ specificity ( $100 \%$ for tension headaches and $95 \%$ for migraine). False-positive screens occurred primarily among individuals who had experienced headaches hours to days before developing a febrile illness (for example, malaria). Validation of the screening questionnaire was car- 
ried out in Neurology clinic of the department of medicine, University of Nigeria Teaching Hospital Enugu [13].

Data obtained were manually sorted and coded into a personal computer. The study protocol was approved by the ethics committee of the University of Nigeria Teaching Hospital Enugu.

Case definition: A diagnosis of migraine or TTH was made using ICHD-III beta [31]. If a subject responded " $\geq 15$ days" to the question "on the average, how often do you have such headaches in a month over the past 3 months?", he/she was classified as having $\mathrm{CDH}$. A diagnosis of $\mathrm{CM}$ or CTTH was assigned if a $\mathrm{CDH}$ subject's headaches met the diagnostic criteria for chronic migraine and chronic tension type headache [32]. See Figure 1.

\subsection{Analyses}

For database management and statistical analyses, we used the SPSS version 22 (Chicago IL, USA). Data were presented in tables. For continuous variables, mean values and $95 \%$ confidence interval were calculated. The prevalence of different types of headache was expressed as percentages and the odds ratio calculated. Mean values were compared using the independent $t$ test. For multiple comparisons ANOVA was used. In all, $\mathrm{p}$ value of $<0.05$ was regarded as significant with $95 \%$ confidence interval. Conclusions were drawn at the level of significance.

Silberstein and Lipton Revised Criteria for Chronic Migraine*

A. Daily or almost daily ( $>15$ days/month) head pain for $>1$ month

B. Average headache duration of $>4$ hours/day (if untreated)

C. At least one of the following:

1) History of episodic migraine meeting any International Headache Society (IHS) criteria 1.1 to 1.6

2) History of increasing headache frequency with decreasing severity of migrainous features over at least 3 months

3) Headache at some time meets IHS criteria for migraine 1.1 to 1.6 other than duration

D. Does not meet criteria for new daily persistent headache or hemicrania

Continua

E. Not attributed to another disorder

New International Headache Society Criteria for Chronic Tension-Type Headache ${ }^{33}$

A. Headache occurring on 15 days per month on average for $>3$ months

(>180 days per year) and fulfilling criteria B-D

B. Headache lasts hours or may be continuous

C. Headache has at least two of the following characteristics:

1. bilateral location

2. pressing/tightening (nonpulsating) quality

3. mild or moderate intensity

4. not aggravated by routine physical activity such as walking or

climbing stairs

D. Both of the following:

1. no more than one of photophobia, phonophobia, or mild nausea

2. neither moderate or severe nausea nor vomiting

E. Not attributed to another disorder

Figure 1. Diagnostic criteria for chronic migraine and tension type headache [32]. 


\section{Results}

Out of the 500 questionnaires distributed during the survey, 449 (89.8\%) were returned and were analyzed. Most of the respondents were females 264 (58.8\%). The male to female ratio was 1:1.4. The age range was 19 - 33 years with a mean of 23.2 years (95\% CI, 22.9 - 23.5): (males-24.2 (95\% CI, 23.7 - 24.7) and females 22.5 (95\% CI, $22.2-22.8$ ) years, $\mathrm{p}=0.012$. The age and sex distribution is shown in Table 2.

\subsection{Primary Headache}

The gender distribution of primary headaches among the students is shown in Table 2. The lifetime prevalence of primary headache was $89.8 \%$ (95\% CI 87 92.6); similar in males $88.6 \%$ (95\% CI 84.1 - 93.2) and females $90.5 \%$ (95\% CI 87 - 94.1) $\mathrm{p}=0.52$.

\subsection{Migraine and Tension Type Headaches}

The distribution of migraine, TTH and their characteristics is also shown on Table 3 and Table 4. The prevalence of migraine was $8.9 \%$ (95\% CI $6.3-11.5$ ) while for females 10.6\% (95\% CI 6.9 - 14.3) and males $6.5 \%$ (95\% CI 3.3 - 10), p $=0.13$. Migraine without aura in this study took the higher proportion of migraine headache $(73 \%)$. The proportion of migraine with aura was $27 \%$ of migraine headache in general. TTH had an overall prevalence of $22.9 \%$ (95\% CI 19.1 - 26.8), males 15.1\%, (95\% CI 10 - 20.3) and females 28.4\%, (95\% CI 23 33.8) $\mathrm{p}<0.01$ among the student population.

Migraine and TTH headaches (MTH) co-existed in 5.8\% (95\% CI $3.6-8$ ) of the students (males 3.8\%, 95\% CI $0.7-5.8$, females $7.2 \%$, 95\% CI $4.1-10.3$ ). The gender distribution of primary headaches is shown in Table 3.

\subsection{Chronic Daily Headache}

The overall prevalence of $\mathrm{CDH}$ was 38 (8.5\%); CM was 2.9\% (95\% CI 1.3 - 4.4) and CTTH was $3.1 \%$ (95\% CI, 1.5 - 4.7) (Table 4). The male to female ration of CM was 0.8:1 and of CTTH it was 1:1. There were no significant differences in the sex distribution of CM and CTTH. The overall rate of medical consultation was $54.8 \%$. In all headache categories the consultation rate was more than $80 \%$ (Table 4).

Table 2. Sex distribution of characteristics of headache among the students.

\begin{tabular}{ccccc}
\hline & Males & Female & Total & $\mathrm{p}$ \\
& $\mathrm{N}(\%)$ & $\mathrm{N}(\%)$ & $\mathrm{N}(\%)$ & Value \\
\hline \#Age Groups (years) & - & - & - & - \\
$<20$ & $25(13.5)$ & $69(26.1)$ & $94(20.9)$ & - \\
$20-24$ & $85(45.9)$ & $151(57.2)$ & $236(52.6)$ & - \\
$25-29$ & $62(33.5)$ & $41(15.5)$ & $103(22.9)$ & - \\
$>30$ & $13(7)$ & $3(1.1)$ & $16(3.6)$ & $<0.01$ \\
- & - & - & - & - \\
Total & $185(41.2)$ & $264(58.8)$ & $499(100)$ & $<0.01$ \\
\hline
\end{tabular}

"Sample population. 
Table 3. Sex distribution of migraine and other types of headache.

\begin{tabular}{|c|c|c|c|c|c|c|}
\hline Types of headache & $\begin{array}{c}\text { Males } \\
\mathrm{N}(\%, 95 \% \mathrm{CI})\end{array}$ & $\begin{array}{l}\text { Female } \\
\text { N (\%) }\end{array}$ & $\begin{array}{l}\text { Total } \\
\mathrm{N}(\%)\end{array}$ & OR & $95 \%$ CI & p-value \\
\hline Primary headache & $164(88.6,84.1-93.2)$ & $239(90.5,87-94.1)$ & $403(89.8,87-92.6)$ & 1.224 & $0.663-2.260$ & 0.52 \\
\hline $\mathrm{CDH}$ & $19(10.3,5.9-14.6)$ & $19(7.2,4.1-10.3)$ & $38(8.5,5.9-11)$ & 0.678 & $0.348-1.318$ & 0.25 \\
\hline Migraine & $12(6.5,2.9-10)$ & $28(10.6,6.9-14.3)$ & $40(8.9,6.3-11.5)$ & 1.710 & $0.846-3.459$ & 0.13 \\
\hline Migraine with aura & $3(1.6,0.2-3.4)$ & $8(3,1-5.1)$ & $11(2.4,1-3.9)$ & 2.105 & $0.475-9.338$ & 0.24 \\
\hline Migraine without aura & $9(4.9,1.8-8)$ & $20(7.6,4.4-10.8)$ & $29(6.5,4.2-8.7)$ & 1.618 & $0.718-3.648$ & 0.32 \\
\hline $\mathrm{CM}$ & $6(3.2,0.7-5.8)$ & $7(2.7,0.7-4.6)$ & $13(2.9,1.3-4.4)$ & 1.264 & $0.330-4.843$ & 0.73 \\
\hline Tension headache & $28(15.1,10-20.3)$ & $75(28.4,23-33.8)$ & $103(22.9,19.1-26.8)$ & -2.225 & $1.373-3.606$ & $<0.01$ \\
\hline CTTH & $6(3.2,0.7-5.8)$ & $8(3,1-5.1)$ & $14(3.1,1.5-4.7)$ & 0.932 & $0.318-2.733$ & 0.9 \\
\hline Migraine/TTH & $7(3.8,1-6.5)$ & $19(7.2,4.1-10.3)$ & $26(5.8,3.6-8)$ & 1.972 & $0.812-4.792$ & 0.13 \\
\hline Unclassified & $152(82.2,76.6-87.7)$ & $179(67.8,62.2-73.4)$ & $331(73.7,69.6-77.8)$ & 0.457 & $1.064-0.782$ & $<0.01$ \\
\hline $\mathrm{CH}$ & $10(5.4,2.1-8.7)$ & $8(3,1-5.1)$ & $18(4,2.2-5.8)$ & 0.655 & $0.182-2.356$ & 0.52 \\
\hline Total & $185(41.2)$ & $264(58.8)$ & $449(100)$ & -- & -- & $<0.01$ \\
\hline
\end{tabular}

Odds ratio for headache and no headache.

Table 4. Age distribution and consultation pattern in different types of headache.

\begin{tabular}{|c|c|c|c|c|c|c|}
\hline & $\begin{array}{l}\text { Migraine } \\
\mathrm{N}(\%)\end{array}$ & $\begin{array}{l}\text { Tension } \\
\mathrm{N}(\%)\end{array}$ & $\begin{array}{l}\text { Migraine and } \\
\text { Tension N (\%) }\end{array}$ & $\begin{array}{c}\text { Chronic Headache } \\
\text { N (\%) }\end{array}$ & $\begin{array}{c}\text { Chronic } \\
\text { Migraine N (\%) }\end{array}$ & $\begin{array}{c}\text { Chronic TTH } \\
\mathrm{N}(\%)\end{array}$ \\
\hline \multicolumn{7}{|c|}{ Age Groups (years) } \\
\hline$<20$ & $7(7.4)$ & $24(25.5)$ & $4(15.4)$ & $13(13.8)$ & $4(4.3)$ & $6(3.2)$ \\
\hline $20-24$ & $24(10.2)$ & $59(25)$ & $18(7.6)$ & $16(6.8)$ & $4(1.7)$ & $5(1.3)$ \\
\hline $25-29$ & $8(7.8)$ & $18(17.5)$ & $4(3.9)$ & $6(5.8)$ & $4(3.9)$ & $3(1)$ \\
\hline$\geq 30$ & $1(6.2)$ & $2(12.5)$ & - & $3(18.8)$ & $1(6.3)$ & - \\
\hline Consultation & $36(90)$ & $84(81.6)$ & $23(88.5)$ & $34(89.5)$ & $12(92.3)$ & $13(92.8)$ \\
\hline Total & $40(8.9)$ & $103(22.9)$ & $26(5.8)$ & $38(8.5)$ & $13(2.9)$ & $14(3.1)$ \\
\hline
\end{tabular}

\section{Discussion}

Headache is a common neurologic disorder worldwide [1]-[14]. The lifetime prevalence of primary headaches among medical and nursing students in this study was higher than the regional and continental average [15] and previous studies from Nigeria [1] [3] [6]-[13]. Similar to a previous study from the region there was no significant difference between males and females [13]. Wide differences exist in the prevalence of primary headaches in Nigeria. This may be due to the period studied (1-year versus lifetime prevalence), genetic, environmental factors, the age group studied, work place environment and weather conditions. Stressful academic activities and rigorous students' life may be contributory to high prevalence of primary headache among the students.

The lifetime prevalence of migraine in this study (as well as in males and females) is within the range reported among undergraduates elsewhere in SSA [1] [2] [3] [7] [15] [33]. The male: female of 1:1.4 is similar to the continental average as well as local reports [13] [14] [17]. Migraine without aura had the higher proportion than migraine with aura in the study. Similar results have been ob- 
tained from earlier studies [13] [34].

The prevalence of TTH (22.9\%) was similar to the prevalence range previously reported from studies conducted among students in SSA [1] [2] [3] [7] [33], and within the global range of $12 \%-78 \%$ [14]. TTH was almost 3 times more prevalent than migraine; however unlike migraine it was significantly more common among females. The epidemiology of TTH has been shown to differ from region to region [15]. In South East Nigeria, the prevalence of TTH ranged from $13.8 \%$ - 36.8\% [1] [13]. See Table 1. The prevalence of TTH in this study was higher than the WHO reported prevalence of TTH in SSA of 1.7\% [34].

Migraine often co-exists with TTH [35]. TTH in migraineurs may be different from episodic tension-type headache [35] [36] [37] and has been reported to be similar in people with migraine and in non migraineurs [38]. The rate of migraine co-existing with TTH in this study is $5.8 \%$ higher than $0.8 \%$ reported by Schramm et al. [38]. The reason for this is not known. Whether migraine and TTH are separate entities or a continuum remains controversial. As headache frequency increases, the phenotypic spectrum of individual headache episodes broadens, and the clinical distinction between migraine and TTH may become less obvious. Migraine and TTH may also aggravate and precipitate each other possibly due to overlapping trigger factors. Furthermore, both disorders may share common pain characteristics hence making misdiagnosis very likely [32] [39].

$\mathrm{CDH}$ represents a heterogeneous group of headache disorders with a global prevalence of $3 \%$ - 5\% [32] [39]. The epidemiology of $\mathrm{CDH}$ varied from study to study just like other primary headaches. Few studies have reported on the prevalence of $\mathrm{CDH}$ in SSA. Hainamot et al. [16] reported a prevalence of $1.7 \%$ in Ethiopia while Mbewe et al. [17] from Zambia reported a 1-year prevalence of $11.5 \%$ [12]. In Nigeria, a prevalence of $17 \%$ has been reported among medical students [1]. Outside the continent, relatively higher prevalence has been found in Georgia [23] and Brazil [24]. The relatively high prevalence in this study is difficult to explain but high rate of caffeine consumption and use of over the counter analgesic may be contributory [32] [35] [39].

$\mathrm{CM}$ and $\mathrm{CTTH}$ may account for more than $60 \%$ of the $\mathrm{CDH}$ population [18]-[24] and may evolve from episodic forms [32]. Furthermore, medication overuse may be implicated in some patients. Therefore, it is theoretically possible for a patient to have both these diagnoses. The prevalence and sex distribution of $\mathrm{CDH}$ in the present study is different from previous studies [18]-[24].

Headaches represent one of the most challenging neurological disorders in SSA considering the numerous differential diagnosis and its variable intensity. It takes a lot of toll on the sufferers, family and coworkers and employers and is fraught with personal and societal consequences. In SSA, where there are few headache specialists and exposure to the discipline is not adequate during medical training [27] primary headaches remain under diagnosed. Overall, the rate of medical consultation was $54.8 \%$. It was more than $80 \%$ for all headache subtypes 
studies; reaching almost $93 \%$ for CTTH. Though the prevalence of $\mathrm{CDH}$ in the community is about $3 \%-5 \%$ of the population, [15] it accounts for the bulk of out-patient visits for headache [32]. The high proportion of medical consultation in this study may be attributed to quick and cheap access to care in a teaching hospital setting. Students may seek care from their senior colleagues, junior doctors or from the school health center which is usually free. Furthermore, they may buy medication based on past experiences instead of seeking proper care. Though this study was conducted in a hospital setting the possibility of using alternative medicine could not be totally ruled out. In Lagos, South West Nigeria only $19.6 \%$ of all primary headache sufferers, $67.7 \%$ of migraineurs and $16.1 \%$ of TTH sufferers sought orthodox medical attention respectively.

The main strength of this study is in determining the prevalence of subtypes of primary headaches among medical and nursing students in SSA. To the best of our knowledge this is the first time the prevalence of CM, CTTH and migraine co-existing with TTH was studied in Nigeria. Though this study was limited to medical and nursing students; it is representative of undergraduate students' population in Nigeria and youths in the community. Mental stress and other factors such as poor feeding habits, excessive use of caffeine and other stimulants that may precipitate and sustain primary headaches are common among students and youths.

\section{Limitations}

The current study was subject to some limitations. Although clinical examinations were not done, the use of ICDH-II criteria mitigated the effect of these to the barest minimum. Students with medication overuse headache, hemicrania continua and other forms of $\mathrm{CDH}$ were not included in the present study. The knowledge of over-the-counter-drugs may increase the likelihood of medication overuse headache especially in those with $\mathrm{CDH}$. The study could have been influenced by recall bias because it is possible that some of the participants did not readily recall the characteristics of the headaches they had in the past. All the data were self-reported and there was no supporting medical records or data accessed. The strict use of ICDH II may underestimate mild forms of primary headaches. The most recent version of headache classification (ICHD-3beta) was not used; however, there are no significant changes between ICHD-II and ICHD-3beta in the criterion for the main headache subtypes discussed in this manuscript.

\section{Conclusion}

Headache is a common health problem among medical and nursing students in Enugu South East Nigeria where $89.8 \%$ of respondents have had primary headaches. The prevalence of migraine, TTH and chronic daily headache was $8.9 \%$, $22.9 \%$ and $8.5 \%$ respectively. Headaches therefore, represent one of the most challenging neurological disorders in Sub-Saharan Africa where most sufferers 
do not have access to specialist care.

\section{Acknowledgements}

The authors would like to acknowledge the Medical and Nursing students for their support as well as Miss Loveth Emmanuel, Secretary for Neurology and EEG services, Mount Carmel Hospital Enugu, for her help in the office.

\section{Conflicts of Interest}

The authors declare no conflicts of interest regarding the publication of this paper.

\section{References}

[1] Ezeala-Adikaibe, A.B., Ekenze, O.S., Onwuekwe, I.O. and Ulasi, I.I. (2012) Frequency and Pattern of Headache among Medical Students at Enugu, South East Nigeria. Nigerian Journal of Medicine, 21, 205-208.

[2] Ogunyemi, A.O. (1984) Prevalence of Headache among Nigerian University Students. Headache: The Journal of Head and Face Pain, 24, 127-130. https://doi.org/10.1111/j.1526-4610.1984.hed2403127.x

[3] Kolawole, W.W. and Asuwemhe, J.U. (2009) Migraine: Prevalence and Associated Disability among Nigerian Undergraduates. Canadian Journal of Neurological Sciences, 36, 216-221. https://doi.org/10.1017/S0317167100006570

[4] Onwuekwe, I.O., Ezeala-Adikaibe, B.A. and Ekenze, O.S. (2012) Neurological Disease Burden in Two Semi-Urban Communities in South East Nigeria. Nigerian Journal of Medicine, 21, 317-319.

[5] Onwuekwe, I.O. and Ezeala-Adikaibe, B. (2011) Prevalence and Distribution of Neurological Disease in a Neurology Clinic in Enugu, Nigeria. Annals of Medical and Health Science Research, 1, 63-67.

[6] Onwuekwe, I.O., Onyeka, T., Aguwa, E., Ezeala-Adikaibe, B., Ekenze, O. and Onuora, E. (2014) Headache Prevalence and Its Characterization amongst Hospital Workers in Enugu, South East Nigeria. Head \& Face Medicine, 10, 48. https://doi.org/10.1186/1746-160X-10-48

[7] Ojini, F.I., Okubadejo, N.U. and Danesi, M.A. (2009) Prevalence and Clinical Characteristics of Headache in Medical Students of the University of Lagos, Nigeria. Cephalagia, 29, 472-477. https://doi.org/10.1111/j.1468-2982.2008.01766.x

[8] Oshinaike, O., Ojo, O., Okubadejo, N., Ojelabi, O. and Dada, A. (2014) Primary Headache Disorders at a Tertiary Health Facility in Lagos, Nigeria: Prevalence and Consultation Patterns. Biomed Research International, Article ID: 782915.

[9] Osuntokun, B., Schoenberg, B., Nottidge, V., Adeuja, A., Kale, O., Adeyefa, A., Bademosi, O. and Bolis, C.L. (1982) Migraine Headache in a Rural Community in Nigeria: Results of a Pilot Study. Neuroepidemiology, 1, 31-39. https://doi.org/10.1159/000110687

[10] Longe, A.C. and Osuntokun, B.O. (1988) Prevalence of Neurological Disorders in Udo, a Rural Community in Southern Nigeria. Tropical and Geographical Medicine, 65, 36-40.

[11] Osuntokun, B.O., Adeuja, A.O., Nottidge, V.A., Bademosi, O., Alumide, A.O., Ige, O., Yarai, F., Scoenberg, B.S. and Bolis, C.L. (1992) Prevalence of Headache and Migrainous Headache in Nigerian Africans: A Community-Based Study. East Afri- 
can Medical Journal, 69, 196-199.

[12] Orji, G.I. and Iloeje, S.O. (1997) Childhood Migraine in Nigeria-I: A Community-Based Study. West African Journal of Medicine, 16, 208-217.

[13] Ezeala-Adikaibe, B.A., Onyekonwu, C., Okudo, G., Onodugo, O., Ekenze, S., Orjioke, C., Chime, P., Ezeanosike, O., Mbadiwe, N., Chikani, M., Okwara, C., Ulasi, I. and Ijoma, U. (2014) Prevalence of Primary Headaches in an Urban Slum in Enugu South East Nigeria: A Door-to-Door Survey. Headache: The Journal of Head and Face Pain, 54, 1601-1610. https://doi.org/10.1111/head.12465

[14] Ofovwem, G.F. and Ofili, A.N. (2010) Prevalence and Impact of Headache and Migraine among Secondary School Students in Nigeria. Headache: The Journal of Head and Face Pain, 50, 1570-1575. https://doi.org/10.1111/j.1526-4610.2010.01776.x

[15] Stovner, L.J., Hagen, K., Jensen, R., Katsarava, Z., Lipton, R.B., Scher, A.I., Steiner, T. and Zwart, J.A. (2007) The Global Burden of Headache: A Documentation of Headache Prevalence and Disability Worldwide. Cephalalgia, 27, 193-210. https://doi.org/10.1111/j.1468-2982.2007.01288.x

[16] Haimanot, T.R., Seraw, B., Forsgren, L., Ekbom, K. and Ekstedt, J. (1995) Migraine, Chronic Tension-Type Headache, and Cluster Headache in an Ethiopian Rural Community. Cephalagia, 15, 482-488. https://doi.org/10.1046/j.1468-2982.1995.1506482.x

[17] Mbewe, E., Zairemthiama, P., Yeh, H., Paul, R., Birbeck, G.L. and Steiner, T.J. (2015) The Epidemiology of Primary Headache Disorders in Zambia: A Population-Based Door-to-Door Survey. Journal of Headache and Pain, 16, 30. https://doi.org/10.1186/s10194-015-0515-7

[18] Lu, S.R., Fuh, J.L., Chen, W.T., Juang, K.D. and Wang, S.J. (2001) Chronic Daily Headache in Taipei, Taiwan: Prevalence, Follow-Up, and Outcome Predictors. $\mathrm{Ce}$ phalalgia, 21, 980-986. https://doi.org/10.1046/j.1468-2982.2001.00294.x

[19] Castillo, J., Munoz, P., Guitera, V. and Pascual, J. (1999) Epidemiology of Chronic Daily Headache in the General Population. Headache, 39, 190-196. https://doi.org/10.1046/j.1526-4610.1999.3903190.x

[20] Scher, A.I., Stewart, W.F., Ricci, J.A. and Lipton, R.B. (2003) Factors Associated with the Onset and Remission of Chronic Daily Headache in a Population Based Study. Pain, 106, 81-89. https://doi.org/10.1016/S0304-3959(03)00293-8

[21] Prencipe, M., Casini, A.R., Ferretti, C., Santini, M., Pezzella, F., Scaldaferri, N. and Culasso, F. (2001) Prevalence of Headache in an Elderly Population: Attack Frequency, Disability, and Use of Medication. Journal of Neurology, Neurosurery and Psychiatry, 70, 377-381. https://doi.org/10.1136/jnnp.70.3.377

[22] Wang, S.J., Fuh, J.L., Lu, S.R., Liu, C.Y., Wang, P.N. and Liu, H.C. (2000) Chronic Daily Headache in Chinese Elderly: Prevalence, Risk Factors, and Biannual Follow-Up. Neurology, 54, 314-319. https://doi.org/10.1212/WNL.54.2.314

[23] Katsarava, Z., Dzagnidze, A., Kukava, M., Mirvelashvili, E., Djibuti, M., Janelidze, M., Jensen, R., Stovener, L.J. and Steiner, T.J. (2009) Lifting the Burden: The Global Campaign to Reduce the Burden of Headache Worldwide and the Russian Linquistic Subcommittee of the International Headache Society. Primary Headache Disorders in the Republic of Georgia: Prevalence and Risk Factors. Neurology, 73, 1796-1803. https://doi.org/10.1212/WNL.0b013e3181c34abb

[24] Queiroz, L.P., Peres, M.F., Kowacs, F., Piovesan, E.J., Ciciarelli, M.C., Souza, J.A. and Zukerman, E. (2008) Chronic Daily Headache in Brazil: A Nationwide Population Based Study. Cephalalgia, 28, 1264-1269. 
https://doi.org/10.1111/j.1468-2982.2008.01670.x

[25] D’Amico, D., Grazzim, L., Usai, S., Raggi, A., Leonardi, M. and Bussone, G. (2011) Disability in Chronic Daily Headache: State of the Art and Future Directions. Neurological Sciences, 32, S71-S76. https://doi.org/10.1007/s10072-011-0552-1

[26] Munakata, J., Hazard, E., Serrano, D., Klingman, D., Rupnow, M.F.T., Tierce, J., Reed, M. and Lipton, R.B. (2009) Economic Burden of Transformed Migraine: Results from the American Migraine Prevalence and Prevention (AMPP) Study. Headache, 49, 498-508. https://doi.org/10.1111/j.1526-4610.2009.01369.x

[27] Steiner T. Atlas of Headache Disorders and Resources (2011) A Collaborative Study by the World Health Organization and Lifting the Burden. A Product of the Global Campaign against Headache. World Health Organization.

[28] Karli, N., Zarifoğlu, M., Ertaş, M., Saip, S., Öztürk, V. and Bıçakçı, Ş. ((2006) Economic Impact of Primary Headaches in Turkey: A University Hospital-Based Study: Part II. Journal of Headache and Pain, 7, 75-82. https://doi.org/10.1007/s10194-006-0273-7

[29] Timothy, S.Y., Mava, Y. and Bwala, A.Y. (2012) Impact of Acute Migraine Headache amongst University Students in Northeastern Nigeria. International Research Journal of Pharmacy, 3, 134-136.

[30] Patel, V., Simbine, A.P., Soares, I.C., Weisss, H.A. and Wheeler, E. (2007) Prevalence of Severe Mental and Neurological Disorders in Mozambique: A Population-Based Survey. The Lancet, 370, 1055-1060. https://doi.org/10.1016/S0140-6736(07)61479-2

[31] Headache Classification Committee of the International Headache Society (2013) The International Classification of Headache Disorders. Cephalalgia, 33, 629-808.

[32] Dodick, D.W. (2006) Chronic Daily Headache. New England Journal of Medicine, 354, 158-165. https://doi.org/10.1056/NEJMcp042897

[33] Amayo, E.O., Jowi, J.O. and Njeru, E.K. (2002) Headache Associated Disability in Medical Students at the Kenyatta National Hospital, Nairobi. East African Medical Journal, 79, 519-523. https://doi.org/10.4314/eamj.v79i10.8813

[34] Alzoubi, K.H., Mhaidat, N., Al Azzam, S., Khader, Y., Salem, S., Issaifan, H. and Haddadin, R. (2009) Prevalence of Migraine and Tension-Type Headache among Adults in Jordan. Journal of Headache and Pain, 10, 265-270. https://doi.org/10.1007/s10194-009-0122-6

[35] Mathew, N.T. (2005) Chronic Daily Headache. In: Evans, R.W. and Matthew, N.T., Eds., Handbook Headache, Lippincott Williams \& Wilkins, Philadelphia, 113-115.

[36] World Health Organization (2004) Headache Disorders. Fact Sheet No. 277.

[37] Ulrich, V., Russel, M.B., Jensen, R. and Olesen, J. (1996) A Comparison of Tension-Type Headache in Migraineurs and in Non-Migraineurs: A Population-Based Study. Pain, 67, 501-506. https://doi.org/10.1016/0304-3959(96)03164-8

[38] Schramm, S.H., Obermann, M., Katsarava, Z., Diener, H., Moebus, S. and Yoon, M. (2013) Epidemiological Profiles of Patients with Chronic Migraine and Chronic tension-Type Headache. Journal of Headache and Pain, 14, 40. https://doi.org/10.1186/1129-2377-14-40

[39] Ahmed, F., Parthasarathy, R. and Modar, K. (2012) Chronic Daily Headaches. Annals of Indian Academy of Neurology, 15, S40-S50.

https://doi.org/10.4103/0972-2327.100002 